\title{
Descolonização do Imaginário e a Instituição Universitária: caminhos possíveis na reconfiguração de representações estereotipadas sobre os indígenas brasileiros
}

\author{
Descolonización del Imaginario y la Institución Universitaria: caminos \\ posibles en la reconfiguración de representaciones estereotipadas sobre \\ los indígenas brasileños
}

\author{
Decolonization of the Social Imaginary and the Universitary Institutions: \\ possible ways for the reconfiguration of stereotyped representation of the \\ Brazilian indigenous person
}

\author{
Ma. Lia Vieira Ramalho Bastos ${ }^{1}$
}

\begin{abstract}
Resumo
Este estudo visa refletir sobre o papel das instituições universitárias e seus desafios na desconstrução de discursos coloniais que, ainda na contemporaneidade, se mantêm arraigados junto ao imaginário popular da sociedade brasileira promovendo, além da reprodução de representações alienantes (BHABHA, 1998), sobre a população indígena, sua exclusão e silenciamento. O indígena na sociedade brasileira ocupa um "não-lugar" (AUGÉ, 1994), o lugar da invisibilidade, da marginalidade, do entre fronteiras, o lugar do outro, ou como se refere Trouillot (2003), está posicionado na "fenda selvagem". As instituições universitárias, por meio de políticas afirmativas efetivas e da elaboração de novas epistemologias baseadas nos saberes não-oriundos do colonialismo ocidental, por exemplo, podem potencializar o desenvolvimento de processos de descolonização de pensamentos e imaginários. Suas ramificações podem gerar transformações não apenas no espaço universitário, mas na sociedade de forma mais ampla, tornando-a mais diversa, inclusiva e igualitária ao fornecer possibilidades para reverter aquele quadro composto por estereótipos, invisibilidade e discriminação que vem sendo vivenciado pela população indígena desde a colonização. Seguindo por esta perspectiva, buscarei demonstrar, além das contribuições das instituições universitárias para o processo de descolonização dos imaginários, pensamentos e saberes, as complexidades empreendidas em processos de pós-colonialismo que trazem consigo conflitos e disputas, neste caso pela reconfiguração de representações sobre os povos indígenas, travados no campo simbólico e refletidos no campo social.
\end{abstract}

Palavras-Chave: descolonização; imaginário popular; indígenas; políticas afirmativas; pós-colonialismo.

\section{Resumen}

Este estudio visa reflejar sobre el papel de las instituciones y sus desafios en la desconstrucción de discursos coloniales que, aún en la contemporaneidad, se mantiene arraigados junto al imaginario popular de la sociedad brasileña promoviendo, además de la reproducción de representaciones alienantes (BHABHA, 1998), sobre la populación indigena, su exclusión y silenciamiento. El indigena en la sociedad brasileña ocupa un "no-lugar" (AUGÉ, 1994), el sitio de la invisibilidad, de la marginalidad, del entre fronteras, el lugar del otro, o como si refiere Trouillot (2003), está posicionado en el "nicho del salvaje". Las instituciones universitarias, por medio de políticas afirmativas efectivas y de la elaboración de nuevas epistemologías basadas en los saberes nooriundos del colonialismo occidental, por ejemplo, pueden potencializar el desarrollo de procesos de descolonización de pensamientos e imaginarios. Sus ramificaciones pueden generar transformaciones no apenas

1 (Mestra em Cultura e Territorialidades; Universidade Federal Fluminense - UFF; Niterói, Rio de Janeiro, Brasil; lia.v.bastos@gmail.com) Trabalho apresentado no I Seminário Latino-Americano de Estudos em Cultura - SEMLACult, Foz do Iguaçu/PR, Brasil, 2017. 
en el espacio universitario, pero en la sociedad de forma más amplia, tornándola más diversa, inclusiva e igualitaria al fornecer posibilidades para revertir aquel cuadro compuesto por estereotipos, invisibilidad y discriminación que viene siendo vivenciados por la población indígena desde la colonización. Siguiendo por esta perspectiva, buscaré demostrar, además de las contribuciones de las instituciones universitarias para el proceso de descolonización de los imaginarios, pensamientos y saberes, las complexidades emprendidas en procesos de pos-colonialismo que traen consigo conflictos y disputas, en este caso por la reconfiguración de representaciones sobre los pueblos indígenas, trabados en el campo simbólico y reflejados en el campo social.

Palabras claves: descolonización; imaginario popular; indígenas; políticas afirmativas; pos-colonialismo.

\section{Abstract}

This study aims at reflecting on the role of the University and its challenges in the deconstruction of colonial discourse which is, until our days, deeply entrenched in the imaginary of the Brazilian society, promoting, besides the reproduction of alienating representations (BHABHA, 1998) about the indigenous population, their exclusion and silencing. The indigenous person occupies a "non-place" (AUGÉ, 1994) in the Brazilian society, the place of invisibility and marginality, a place between the boundaries, the place of the other, or as mentioned by Trouillot (2003), the indigenous person is positioned in the "savage slot". The Universitary Institutions, by means of effective affirmative actions and the formulation of new epistemologies based on knowledge which does not originate in Western colonialism, for example, may potentialize the development of the process of decolonization of thought and social imaginary. The ramifications of this process may create transformations, not just within the university space, but also in society in a broader way, causing it to become more diverse, inclusive and egalitarian by providing possibilities to reverse that view composed by stereotypes, invisibility and discrimination which has been experienced by the indigenous population since the colonization. Under this perspective, the aims of this study are to demonstrate the contributions of the Universitary Institutions for the process of decolonization of the social imaginary, thought and knowledge, as well as the complexities undertaken in postcolonialism processes which bring along conflicts and dispute, in this case for the reconfiguration of the representations about the indigenous people in the symbolic field and reflected in the social field.

Keywords: decolonization; social imaginary; indigenous person; affirmative actions; postcolonialism.

\section{Introdução}

O marco oficial do início da história brasileira é a chegada dos portugueses a estas terras em 1500, o qual foi amplamente difundido como o "descobrimento" do Brasil. A utilização deste termo nos leva a pensar que nossa história somente passou a existir após este acontecimento, ignorando o fato da existência de uma população nativa que, segundo Darcy Ribeiro (1995), poderia ser estimada em 5 milhões de habitantes naquele período. Hoje, de acordo com os dados do Censo Demográfico realizado pelo IBGE em 2010, esta parcela da população brasileira não chega a 900 mil.

A colonização portuguesa gerou um processo de "depopulação" indígena de forma brutal no Brasil (TEIXEIRA, 1995, p.295). Além do extermínio em massa, estes povos foram caçados e escravizados, foram expostos a diversas doenças contagiosas que para eles eram mortais, tiveram seus territórios de subsistência reduzidos pela ocupação portuguesa e em muitos casos obrigados a viver em aldeamentos fixos, limitando e extinguindo suas práticas 
culturais. Além de toda essa violência física enfrentada pelos povos indígenas brasileiros, é relevante também apontarmos para a violência simbólica sofrida nos campos social, político e, principalmente, cultural, refletida ainda nos dias atuais. As mais diversas tentativas de diminuir, e até mesmo extinguir, práticas e referenciais culturais indígenas vieram sendo utilizadas desde o período colonial por portugueses e jesuítas, por considerarem suas nações mais evoluídas e superiores culturalmente. Dentre elas podemos apontar para a construção do que viemos a chamar de discurso colonial. Discursos que afirmavam esta suposta superioridade e que, por meio de sua reprodução e repetição, foram sendo fixados ao longo dos anos junto ao imaginário da população brasileira, se configurando em um processo de negação e distanciamento de referenciais identitário com a cultura indígena.

Conforme Darcy Ribeiro (1995), práticas de dominação e extermínio formatadas a partir da cultura podem se configurar como um processo mais lento e discreto, mas sua atuação age de forma mais profunda e potente junto às sociedades. Como resultado, continua Ribeiro, teríamos a base da sociedade e cultura brasileira edificada como uma implantação colonial europeia com vistas de um plano ideológico sujeito a métodos avançados de ordenação social e a instrumentos de regulação e controle das formas de expressão, promovendo, além do reconhecimento e pertencimento da população oprimida com a cultura praticada e imposta pelo colonizador, ainda um processo de "silenciamento" e “invisibilidade" (OLIVEIRA, 2015) destes povos.

O indígena sempre esteve presente no imaginário popular, mas comumente assumindo o estereótipo de bravo guerreiro, vivendo nas florestas, em suas aldeias, ou como um ser selvagem e primitivo, ou ainda como imprevidente e marginalizado. $\mathrm{O}$ indígena brasileiro sempre ocupou um "não-lugar" (AUGÉ, 1994) em nossa sociedade após a colonização, estando sempre posicionado entre culturas e enfrentando uma "luta de fronteiras" (ANZALDÚA, 2012), sendo elas materiais ou simbólicas. Foram mortos ou expulsos de seus territórios em razão da ganância e dominação do colono, que hoje vemos representados na figura dos grandes latifundiários. Nas áreas urbanas são alvo de estranhamentos, preconceitos e discriminações, pois reproduz-se no imaginário que lugar de índio é na floresta. Então, qual o lugar do indígena em nossa sociedade? Por que suas representações se mantêm, em nosso meio social, imbuídas de tantas ambivalências e estereótipos? Qual o papel dos discursos oficiais na construção destas representações e quais as estratégias dos povos indígenas para sua desconstrução e reconfiguração? Pode o indígena falar? ${ }^{2} \mathrm{O}$ que é preciso para que o

2 Utilizando como referência Gayatri Spivak em Pode o subalterno falar?, 1985. 
indígena se posicione e seja ouvido? Por que os diálogos entre o índio e o não-índio são tão desiguais? Até quando a versão do "colonizador” irá prevalecer?

\section{Para além da "fenda selvagem"}

De acordo com Michel-Rolph Trouillot (2003), as narrativas utópicas sobre o outro, criadas pelo campo discursivo da antropologia, mantêm até hoje o indígena aprisionado dentro do discurso colonialista, posicionado no lugar do outro, ou como se refere Trouillot, enquadrado em uma "fenda selvagem". Um lugar marcado pela diferença, pelo exótico, pelo desconhecido, que conforme Homi Bhabha (1998), é ao mesmo tempo familiar em virtude da reprodução repetitiva de discursos caracterizados por estereótipos, criados a partir de modelos configurados por imagens simplificadoras, pejorativas e distorcidas destes sujeitos. Ainda segundo Bhabha (1998, p.127), a frequente apresentação como degenerado, devido a sua origem racial, que o discurso colonial faz do colonizado à sociedade, mostra-se também como uma estratégia para justificar a necessidade do domínio e do estabelecimento de sistemas e normas de administração e de instrução aos povos "primitivos".

Vemos que o processo colonial, além de gerar diversos problemas ligados à dependência econômica, ao subdesenvolvimento e à marginalização destes povos, atua de forma potente sobre a cultura local, minando, ou até mesmo extinguindo suas práticas e manifestações, conforme demonstrado com o estudo de caso sobre a cidade de Niterói (BASTOS, 2015). Estas estratégias das quais o discurso colonial se utiliza, acarretam ao sujeito sentimentos de ambivalências e confrontos identitários, pois fazem com que ele se reconheça através de imagens alienantes e distorcidas, legitimadas e repetidas por aqueles ao seu entorno. Os resultados deste processo, conforme analisa Bhabha em O Local da Cultura (1998), acabam por repercutir em preconceitos, discriminações e exclusões que permanecem vigentes em relação a questões étnicas, culturais ou territoriais nestas sociedades colonizadas, geração após geração.

De acordo com a cronologia da história brasileira, faz muitos séculos que passamos pelo período colonial, no entanto é perceptível que não o superamos, visto que ainda vivemos permeados por seus reflexos, vivenciando dia a dia suas ações e consequências. Stuart Hall (2003, p.56) se posiciona a este respeito argumentando que países que passaram por processos de colonização continuam a vivenciar aquelas condições decorrentes do colonialismo, apresentando uma relativa fragilidade em relação às áreas social, cultural, econômica e militar. Alega que as culturas nativas deslocadas, senão destruídas pelo colonialismo, não são 
inclusivas a ponto de fornecer a base para uma nova cultura nacional ou cívica, corroborando para a continuidade do processo de afastamento e de não reconhecimento entre a população e suas origens culturais identitárias.

Stuart Hall atenta ainda para a ambiguidade gerada pela utilização do termo "póscolonial”, pois a interpretação de seu prefixo como um sentido de encerramento ou conclusão de um processo entraria em conflito com a realidade, já que características diversas deste período continuam presentes e atuantes mesmo como o passar dos anos. Hall sugere então, que para uma utilização menos conflitiva deste termo, podemos interpretar o "pós" como significante de um período posterior, e não de um processo superado.

Assim, entendo que, principalmente a partir dos estudos de Bhabha (1998) e Stuart Hall (2013), há uma complexidade incutida no processo de colonização, e na reprodução por séculos de seus discursos distorcidos e alienantes, que se encontram intrínsecos na formação identitária e cultural dos povos colonizados, inclusive o brasileiro. Segundo Michael Pollak (1992, p.4), “a construção da identidade é um fenômeno que se produz em referência aos outros, em referência aos critérios de aceitabilidade, de admissibilidade, de credibilidade, e que se faz por meio da negociação direta com outros". Por meio desta perspectiva, a argumentação de Hall sobre a identidade se encontrar constantemente em um campo de disputas, torna-se mais inteligível ao considerarmos as diversas questões geradas pelo colonialismo refletidas em estigmas, estereótipos, preconceitos, exclusões, representações ambíguas, distorcidas e alienantes do sujeito colonizado. Porém, apesar de toda complexidade incutida por estes processos, acredito que possam existir caminhos e possibilidades para a desconstrução destes discursos que rotulam e excluem a participação igualitária da população indígena em nossa sociedade.

Bourdieu (1990, p.166) argumenta que "para mudar o mundo, é preciso mudar as maneiras de fazer o mundo, isto é, a visão de mundo e as operações práticas pelas quais os grupos são produzidos e reproduzidos". Ao compreendermos o termo discurso por seu viés pragmático, como criador de ato que constrói mundos, que exerce efeito e causa consequências reais sobre o meio social, podemos reconhecer como factíveis os efeitos que o discurso colonial gerou, e vem gerando, em nossa sociedade, principalmente sobre as populações indígenas. Vejo no desenvolvimento de um processo de descolonização, partindo da desconstrução destes discursos fundamentados em uma lógica colonialista eurocêntrica, a possibilidade de transformação dessa visão de mundo estereotipada e estigmatizada sobre o indígena, em outra mais condizente com a realidade. Uma nova visão, na qual suas representações possam também ser construídas por si e não apenas pelo outro, possibilitando 
que a imagem do indígena, configurada a partir de imaginários fantásticos, narrativas utópicas e senso comum, possa se deslocar e transpor as fronteiras da "fenda selvagem", e assim, consiga o indígena atuar como sujeito protagonista de sua história e da sociedade brasileira de forma mais ampla e em maior equidade.

\section{As instituições universitárias e o processo de descolonização de imaginários e de reconfiguração das representações indígenas}

É possível ver, por meio de políticas públicas direcionadas à educação, uma porta de acesso para que transformações desta "visão de mundo" sobre o indígena, que viemos construindo desde o período colonial, possam ocorrer. A Lei $\mathrm{N}^{\mathrm{o}} 11.645$ de março de 2008, que estabelece a obrigatoriedade do ensino da história e da cultura indígena nos ensinos fundamental e médio, mostrou-se como um dos caminhos para esta mudança. No entanto, a eficácia deste processo continuará comprometida se não forem estimuladas a inclusão sociocultural do indígena, a formação de profissionais de educação capacitados e o desenvolvimento de materiais didáticos que auxiliem na desconstrução de representações estigmatizadas e idealizadas destas populações.

A geração de políticas afirmativas pautadas pela identidade cultural e direcionadas à educação, se mostra de grande valia para que o cumprimento da lei citada anteriormente se concretize em sua plenitude, de forma que estas políticas venham a impulsionar a formação de mais acadêmicos indígenas. E que esses venham contribuir com a formação de outros, visando ocupar espaços nos estabelecimentos de ensino de todo o país, assim como a produção de materiais didáticos mais pertinentes sobre a cultura e a história indígena. $\mathrm{Na}$ verdade, a ampliação do acesso e, consequentemente, da "permanência simbólica e material" (ESTÁCIO, 2015) de indígenas na academia, e em toda a rede de ensino, pode ir além. Pode promover inclusão e integração social, redução de estranhamentos e estreitamento das “distâncias sociais" (BOURDIEU, 1990, p.155), levando à desconstrução de preconceitos e à possibilidade de tornarem-se representação para outros indígenas, como também, autores de suas próprias representações para toda uma sociedade.

As representações sociais, conforme Moscovici (1978), ao entrarem em atuação deixam de ser apenas um guia para o comportamento e passam a gerar transformações ao seu entorno, proporcionando a ocorrência de novas refigurações, atenuando as "estranhezas" e modificando comportamentos e relações ao invés de gerar meras reproduções. Seguindo por estas perspectivas, creio que através das instituições universitárias, via políticas afirmativas 
mais efetivas, transformações possam ocorrer. Transformações estas, figuradas por meio de aplicações de novas epistemologias baseadas nos saberes não-oriundos do colonialismo ocidental, do ingresso de mais discentes e docentes indígenas em seus campi, de uma maior "permanência simbólica e material", como indicamos acima, de indígenas na academia, e da atuação e protagonismo destes sujeitos para se consolidarem representativos e ocuparem o seu espaço de direito, e para assim também estimular que novas representações possam vir a se configurar.

Para além da importância da representatividade indígena nas universidades e nos mais diversos campos societários, precisamos frisar a importância da educação para que mudanças também ocorram em favor da causa indígena. De acordo com Simone Eloy Amado, “a educação se configura como instrumento de grande valia em busca da dignidade garantida pela cidadania brasileira, no que tange à necessidade do protagonismo dos povos indígenas na defesa de seus direitos" (AMADO, 2016). Com a educação "convencional" e com a apropriação de "ferramentas dos brancos", como diz Amado, a relação com o não-índio passa a ser mais igualitária, possibilitando ao indígena construir sua autonomia e buscar por seu protagonismo. Desta forma, mostra-se ser preciso "adquirir conhecimento para estabelecer um diálogo menos desigual" (SOUZA LIMA, 2016, p.17).

Ainda segundo Amado, "quando ingressam nas universidades, esses indígenas vão atrás de um som: o de sua própria voz, que querem ouvir soar tanto nas suas aldeias e comunidades em geral, quanto na própria universidade" (AMADO, 2016, p.50). No entanto, para que isso ocorra em efetivo, um longo caminho ainda precisa ser percorrido. Não basta apenas o sancionamento de leis para política de cotas, é preciso também uma política de ações afirmativas para incentivar, além da inclusão de indígenas no ensino superior, o acompanhamento de sua trajetória, assegurando a permanência na academia até sua formação. A Universidade Estadual de Mato Grosso do Sul conta com ações deste caráter, proporcionadas pelo Projeto Rede de Saberes, que visa a permanência do aluno no ensino superior, e pelo Programa de Formação Superior e Licenciaturas Indígenas (PROLIND), que incentiva a formação de professores indígenas para atuarem nas escolas da aldeia. Porém estas ações, conforme relata Amado, se mostram insuficientes diante da demanda existente no estado, que possui uma população indígena estimada pelo Censo 2010 em mais de 73 mil pessoas.

No que diz respeito a programas de pós-graduação, algumas iniciativas têm sido implantadas. Podemos citar, a título de exemplo, segundo Marcela Stockler Coelho de Souza (2017, p.105), o programa de pós-graduação em Antropologia Social da Universidade de 
Brasília, que aprovou, em 2013, uma política de ações afirmativas que previa a reserva de uma vaga de mestrado e de doutorado para candidatos indígenas. A seleção ocorreria por meio de um processo específico que incluía a apresentação de um dossiê e de uma entrevista, e prova de língua estrangeira não eliminatória disponibilizando, para aqueles não aprovados, um semestre de curso instrumental conveniado com o Instituto de Letras da Universidade. Previa ainda, a prioridade na alocação de bolsas, a provisão de moradia e alimentação. Segundo a antropóloga, estas ações vêm sendo cumpridas parcialmente e com dificuldades, visto que não há uma política de ações afirmativas institucionalizadas no âmbito geral da Universidade de Brasília. No entanto, já as considera como um êxito, pois todas as vagas foram preenchidas e ainda ampliadas nos anos que seguiram a esta implementação.

No estado do Rio de Janeiro, onde venho realizando minha pesquisa, a população indígena estimada pelo Censo 2010 ficou um pouco abaixo de 16 mil pessoas, sendo que destas, quase 7 mil vivem na capital, onde temos duas universidades federais (UFRJ e UNIRIO) e em sua região metropolitana outras duas (UFF e UFRRJ). De acordo com a análise realizada pelo Grupo de Estudos Multidisciplinares da Ação Afirmativa (GEMAA/IESP-UERJ), após dois anos da vigência da Lei $\mathrm{N}^{\circ} 12.711$, de 29 de agosto de 2012, que estabeleceu a obrigatoriedade de cotas para a inclusão social e racial nas universidades públicas, as instituições federais da região sudeste do país já estariam próximas de atingir a meta obrigatória prevista na lei para 4 anos. ${ }^{3}$ Porém, os dados coletados abrangem em totalidade a região sudeste e a porcentagem de cotas não faz distinção entre pretos, pardos e indígenas, dificultando uma visualização mais definida sobre estes cotistas no Rio de Janeiro. No entanto, o que pudemos observar em um primeiro momento é que a presença indígena, configurada por discentes ou docentes nos espaços universitários da capital fluminense e região metropolitana, permaneça ofuscada ou talvez seja imperceptível, apesar da constatação de iniciativas embrionárias com políticas afirmativas direcionadas à população indígena por parte de alguns programas de pós-graduação da rede federal. ${ }^{4}$

\footnotetext{
3 O estudo apresenta, através de dados coletados pelo IBGE, uma população composta por pretos, pardos e indígenas na região sudeste de 43,9\% e a criação em dois anos após a vigência da Lei no 12.711 de 20,6\% de vagas reservadas nas universidades públicas para estas populações, resultando em um índice percentual de inclusão racial de 47\% (DAFLON; FERES JÚNIOR \& MORATELLI, 2014, p.9).
}

4 Como, por exemplo, os Programas de pós-graduação em Antropologia Social e em Linguística e Línguas Indígenas do Museu Nacional/UFRJ, assim como o de Sociologia e Antropologia-PPGSA/IFCS também da UFRJ, o Programa de Pós-graduação em Antropologia da Universidade Federal Fluminense, e o Programa de pós-graduação em Comunicação e Cultura da Universidade Federal do Rio de Janeiro, dentre outros. 


\section{Conclusões}

A partir destas primeiras perspectivas, visto que esta pesquisa se encontra em um processo inicial de desenvolvimento, parto do pressuposto de que por meio das instituições universitárias possam se acionar processos de descolonização dos imaginários e saberes. Que estas possam fornecer a seus atores políticos - neste caso, docentes e discentes - ferramentas e caminhos possíveis para que novas reconfigurações na contemporaneidade venham ocorrer sobre representações fixadas e estereotipadas, desde o período colonial, sobre os indígenas brasileiros.

Compreendo, conforme me foi apontado durante a apresentação deste artigo no I SEMLACult, que a instituição universitária foi forjada e se mantém estruturada em parâmetros colonialistas, assim como suas práticas e epistemologias, e que se configura em um campo permeado por disputas e conflitos, dificultando que transformações mais profundas ocorram em sua estrutura. Porém, vejo que a universidade também é um espaço potencial de discussões, de desenvolvimento do pensamento crítico e político, que pode direcionar a repensar e reformular teorias e conceitos. Isto demonstra que esta instituição não está fixada e encontra-se também sujeita a mudanças, que podem surgir a partir de ações transformadoras internas (GOLDMAN; BANAGGIA, 2017), as quais, consequentemente, serão refletidas externamente. Ainda, conforme Marcio Goldman e Gabriel Banaggia:

\footnotetext{
Se é comum e pertinente o argumento de que não basta a simples inserção de alunos negros e indígenas no mundo acadêmico, como se fosse o caso de formatá-los segundo a mesma lógica branca e elitista que sempre reinou na universidade e serviu como ferramenta de exclusão, tampouco é o caso de afirmar que é impossível acolhê-los antes de uma revolução educacional integral, que nunca se sabe quando exatamente se tornará pronta a aceitar a diferença. Tal cenário implicaria que essa transformação partiria antes de tudo de cima, em vez de considerar que ela talvez só possa ser realizada efetivamente numa relação de igualdade com seus interessados mais diretos em todos os níveis da academia (Idem, 2017, p.27).
}

Apesar da permanência, em nosso cotidiano, da concepção de que a implementação das cotas não proporciona reais transformações para a construção de uma universidade mais diversa, pois a inclusão destes sujeitos seria apenas periférica, as vejo como um primeiro passo a ser percorrido a caminho da decolonialidade e de reparações históricas e sociais. Parto da hipótese que, ao implementar com efetividade políticas afirmativas e "processos desenhados para acolher a diversidade das trajetórias - escolares e existenciais - de sujeitos (individuais e coletivos) histórica, contínua e barbaramente subalternizados da sociedade brasileira" (COELHO DE SOUZA, 2017, p.101), as universidades, por meio de seus atores 
políticos, podem contribuir potencialmente com a desconstrução de discursos coloniais ainda vigentes, ampliar o debate e a elaboração de novas epistemologias baseadas nos saberes nãooriundos do colonialismo ocidental, além de proporcionar uma maior inclusão da população indígena, não apenas no espaço universitário, mas na sociedade de forma mais ampla.

Com um campo de pesquisa pré-definido, direcionado às instituições federais universitárias do Rio de Janeiro, sigo buscando investigar como a implementação de políticas de ações afirmativas para o ingresso e permanência de indígenas na graduação, pós-graduação e no exercício da docência atua junto ao processo de descolonização de imaginários e narrativas. Percebo que nestes últimos anos - mesmo com um número relativamente pequeno de indígenas aqui no estado, se comparado a outros como Mato Grosso do Sul, Amazonas ou Acre, entre outros - ampliou-se a implementação de ações afirmativas para a inclusão de indígenas em programas de pós-graduação vinculados às universidades federais do Rio de Janeiro.

Observo também, que a discussão sobre esta temática vem se estendendo em publicações, debates e eventos, como o Seminário de Ações Afirmativas da Pós-graduação que teve sua segunda edição realizada pela Universidade Federal Fluminense em maio deste ano, e o Grupo de Trabalho sobre Raça e Gênero que vem sendo desenvolvido pelos alunos do Programa de Pós-graduação em Cultura e Territorialidade - PPCULT/UFF, para discutir entre outras coisas, questões relativas a elaboração, implementação e adequação da política de ações afirmativas em atuação junto ao programa.

Com o objetivo de aprofundar esta análise e obter maiores resultados, considero ser preciso a verificação junto aos cursos de graduação e pós-graduação das universidades federais do Rio de Janeiro que nos últimos anos optaram pela implementação destas ações, da efetividade do programa de cotas (Lei $\mathrm{N}^{\circ}$ 12.711/2012) no ingresso de candidatos indígenas e se há uma demanda desta população no estado por estas vagas. Averiguar se as propostas ou ações afirmativas existentes são efetivas ao acompanhamento destes alunos, primando por sua permanência na instituição até a conclusão do curso. Ainda, buscar por graduados e pósgraduados indígenas que compõem o corpo docente destas universidades e compreender como eles se veem e como são vistos no mundo acadêmico e fora deste, para então podermos avaliar se após a apropriação das "ferramentas dos brancos" (AMADO, 2016) houve uma maior equidade entre as relações. Analisar também se dentre os resultados das ramificações geradas a partir das políticas afirmativas incluem-se avanços em relação ao processo de descolonização dos imaginários, pensamentos e saberes, que viabilizem ao indígena 
transpassar fronteiras que venham a enquadrá-lo em uma "fenda selvagem", conforme diria Trouillot.

Por meio deste trabalho, mediante uma breve exposição teórica e metodológica, procurei demonstrar a necessidade de uma análise crítica e mais aprofundada a respeito da influência do processo colonial junto à sociedade brasileira e seus sujeitos. Atentei para a relevância do exercício de políticas de ação afirmativa em instituições universitárias no auxílio a desconstrução de discursos colonialistas, de suas projeções e repercussões na configuração de representações sociais, narrativas e imaginários. Passados mais de 500 anos de colonização, a sociedade brasileira, de forma geral, permanece permeada por pensamentos e discursos colonialistas, principalmente em relação à população indígena que continua sendo rotulada a partir de estereótipos pejorativos incutidos de racismo e preconceito.

\footnotetext{
Não precisamos nos 'fantasiar' de índio para agradar a uma visão sobre nós. Somos indígenas, vivemos na cidade, cursamos a universidade e infelizmente temos que lidar diariamente com questionamentos contrários ao ir para aula ou dar uma palestra de calça jeans, tênis e mochila (In: FREITAS, 2015, p.38).
}

Esta fala dos estudantes do Programa de Educação Tutorial - PET nos mostra com clareza a continuidade da ação do discurso colonial sobre nossa sociedade, identidades e imaginários. Ao mesmo tempo nos aponta para a necessidade e pertinência em descontruirmos estes discursos, seus estereótipos e suas representações alienantes, descolonizando pensamentos e imaginários fundamentados em uma suposta superioridade cultural eurocêntrica ocidental, para que se possa construir uma sociedade mais igualitária e inclusiva em um país multiétnico e multicultural como se configura o Brasil.

\section{Referências}

AMADO, Simone E. Ensino superior para os povos indígenas de Mato Grosso do Sul: desafios, superação e profissionalização. Rio de Janeiro: PPGAS/Museu Nacional/UFRJ, 2016.

ANZALDÚA, Gloria. Borderlands/La Frontera. The new mestiza. San Francisco: Aunt Lute Books, 2012.

AUGÉ, Marc. Não-Lugares: Introdução a uma antropologia da supermodernidade. São Paulo: Papirus, 1994.

BASTOS, Lia V. R. "Niterói, terra de indio": apagamentos, silenciamentos e reapropriações em torno da figura de Araribóia. Dissertação (Mestrado Acadêmico em Cultura e 
Territorialidades) - Universidade Federal Fluminense, Instituto de Arte e Comunicação Social. Niterói, 2015.

BHABHA, Homi K. O Local da Cultura. Belo Horizonte: Ed. UFMG, 1998.

BOURDIEU, Pierre. Espaço social e poder simbólico. In: Coisas Ditas. São Paulo: Brasiliense, 1990.

COELHO DE SOUZA, Marcela S. Contradisciplina: indígenas na pós-graduação e os futuros da antropologia. Revista de Antropologia, São Paulo, v. 60, n. 1, p. 99-116, may 2017. ISSN $1678-9857$.

DAFLON, Verônica Toste; FERES JÚNIOR, João \& MORATELLI, Gabriella. Levantamento das políticas de ação afirmativa 2014: evolução temporal e impacto da Lei $n^{o}$ 12.711 sobre as universidades federais. (IESP-UERJ), n. 4, 2014, pp.1-10.

ESTÁCIO, Marcos A. F. A presença indígena no ensino superior: a experiência da Universidade do Estado do Amazonas. Florianópolis: Anpuh, 2015. pp. 1-14.

FREITAS, Ana Elisa de C. (org.) Intelectuais indígenas e a construção da universidade pluriétnica no Brasil [recurso eletrônico]: povos indígenas e os novos contornos do programa de educação tutorial/conexões de saberes.1. ed. Rio de Janeiro: E-papers, 2015.

GOLDMAN, Marcio; BANAGGIA, Gabriel. A política da má vontade na implantação das cotas étnico-raciais. Revista de Antropologia, São Paulo, v. 60, n. 1, p. 16-34, may 2017. ISSN 1678-9857.

HALL, Stuart. Da diáspora: identidades e mediações culturais. Belo Horizonte: Universidade Federal de Minas Gerais, 2013.

MOSCOVICI, Serge. A representação social da psicanálise. Rio de Janeiro: Zahar, 1978.

OLIVEIRA, Bruno Pacheco de. Quebra a cabaça e espalha a semente. Desafios para um protagonismo indígena. Rio de Janeiro: E-papers, 2015.

RIBEIRO, Darcy. O Povo Brasileiro: A formação e o sentido do Brasil. São Paulo: Companhia de Bolso, 1995.

SOUZA LIMA, Antonio C. de (org.). A educação superior de indígenas no Brasil [recurso eletrônico]: balanços e perspectivas. - 1. ed. - Rio de Janeiro: E-papers, 2016.

TEIXEIRA, Raquel, F., A. “As línguas indígenas no Brasil”. In: SILVA, A., L., da; GRUPIONI, L., D., B. (org.). A temática indígena na escola: novos subsídios para professores de $1^{o}$ e $2^{o}$ graus. Brasília: MEC/MARI/UNESCO,1995. pp. 291-316.

TROUILLOT, Michel-Rolph. "Anthropology and the savage slot: The poetic and politics of otherness" In: Global transformations: Anthropology and the modern world. New York, Palgrave Macmillan, 2003. pp. 7-28. 